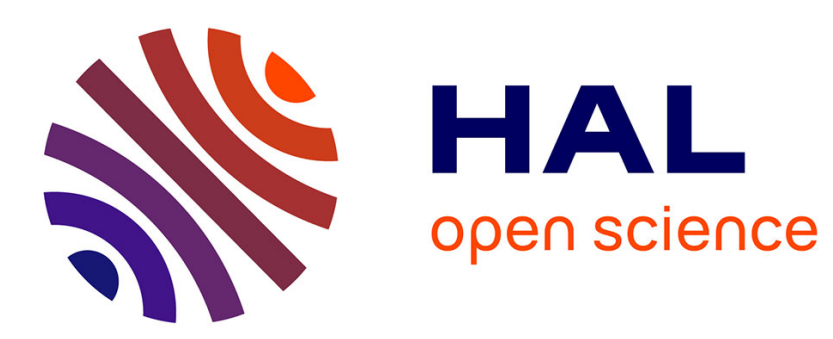

\title{
Near-Infrared Spectroscopy Analysis of Heavy Fuel Oils Using a New Diffusing Support
}

\author{
Nathalie Dupuy, Zeineb Braham, Sandrine Amat, Jacky Kister
}

\section{To cite this version:}

Nathalie Dupuy, Zeineb Braham, Sandrine Amat, Jacky Kister. Near-Infrared Spectroscopy Analysis of Heavy Fuel Oils Using a New Diffusing Support. Applied Spectroscopy, 2015, 69 (10), pp.1137 1143. 10.1366/14-07725. hal-01765181

\section{HAL Id: hal-01765181 \\ https://hal.science/hal-01765181}

Submitted on 12 Apr 2018

HAL is a multi-disciplinary open access archive for the deposit and dissemination of scientific research documents, whether they are published or not. The documents may come from teaching and research institutions in France or abroad, or from public or private research centers.
L'archive ouverte pluridisciplinaire HAL, est destinée au dépôt et à la diffusion de documents scientifiques de niveau recherche, publiés ou non, émanant des établissements d'enseignement et de recherche français ou étrangers, des laboratoires publics ou privés. 


\title{
Near-Infrared Spectroscopy Analysis of Heavy Fuel Oils Using a New Diffusing Support
}

\author{
Nathlie Dupuy, Zeineb Brahem, Sandrine Amat, , Jacky Kister \\ Aix Marseille Université, LISA, EA4672, Equipe METICA, 13397 Marseille Cedex 20, France
}

\begin{abstract}
The characterization of heavy fuel oils (HFOs), used as fuel for boats, requires the analysis of various properties that are essential for engine optimization and pollution control. For some time, nearinfrared (NIR) spectroscopy combined with chemometric treatment of the spectra was used for on-line analysis. This preliminary study included 61 heavy fuels from Europe, America, and Asia with different specifications according to their geographical origin; their refining process; and their physicochemical properties, including density, flash point, viscosity, and sulfur content. We have developed a new method for sampling heavy fuels on a fiberglass cell support. This support offers the advantages of speed, easy implementation, repeatable results, and freedom from problems associated with tank cleaning. Two sample presentations, an integrating sphere and an optical fiber, were used to collect the NIR spectra. A theoretical study of the choice of the value of resolution, scan number, and spectral region was conducted. The best conditions were chosen as a function of the quality of quantitative analysis results on viscosity, sulfur content, flash point, and density. The two collecting methods were compared on the same criteria.
\end{abstract}

Index Headings: Fuel; Near-infrared; NIR; Calculated carbon aromaticity index; CCAl; Sulfur content; Soft independent modeling of class analogy classification; SIMCA; Partial least squares; PLS.

\section{INTRODUCTION}

Heavy fuel oils (HFOs) are products of crude oil refining after a distillation process. According to the nature of the refined crude oil, $10-20 \%$ of it is separated out as HFOs. These heavy fuels are mainly used in boats and power stations. Very complex matrices consisting of chains of hydrocarbons, HFOs have degrees of alkylation between 25 and 200 atoms of carbon These samples also contain high levels of heteroatoms, such as sulfur, nitrogen, and oxygen, as well as metals, including nickel and vanadium. The characterization of HFOs requires the analysis of selected chemical and physical properties. The properties of HFOs depend on the geographical origin of crude oil and on the refining processes. For example, Venezuelan crude oil is known for its high ash content, whereas crude oils from the Middle Bast generally have low sulfur content. The HFOs obtained from those crude oils will present different physicochemical characteristics. For an engine to run optimally, it is essential to have a basic understanding of such fuel characteristics and properties as viscosity, ${ }^{1}$ carbon residue, vanadium content, calculated carbon aromaticity index (CCAI), and flash point, and such contaminants as nitrogen and water, ${ }^{2}$ which affect fuel handling and fuel treatment systems. Although heavy fuels must be in accordance with the specifications required in all countries, the complexity of the refining of crude oils influences the variability of the quality of finished products. Recently, infrared and fluorescence measurements have been used in petroleum development. Investigations studied tank continuity ${ }^{3}$ and evaluated thermal maturity. ${ }^{4,5}$ Among several methods of spectroscopic data interpretation, we highlight the studies of Kister et al.6,7 wherein indexes have been calculated from areas of absorption bands to describe the global structure of oils by Fourier transform infrared spectrometry (FT-IR) and their aromatic structures by synchronous excitation-emission ultraviolet fluorescence. Fourier transform infrared spectrometry was used to determine aliphatic, aromatic, and functionalized compounds for each oil, whereas the condensation degree of aromatic rings has been evaluated by synchronous ultraviolet fluorescence analysis. ${ }^{8-10}$ Traditionally, spectral analysis by chemometrics proved their relevance to analysis of crude oils, ${ }^{11,12}$ petroleum fractions such as gasoline, ${ }^{13}$ and lubricant oils. ${ }^{14}$ Near-infrared spectroscopy ${ }^{15}$ was used to control the oil refining process. In this work, a new methodology for heavy fuels analysis is proposed, with a new sampling method for heavy fuels. This new sampling technique was tested to develop calibrations for some physicochemical parameters of the fuel samples to determine whether they could be recognized as conforming to international standards. Simultaneously, the same analysis could be done on the spectral data to confirm the diagnostic obtained on the physicochemical parameters. Then, the main parameters, such as density, CCAl, and viscosity, and nitrogen, vanadium, sulfur, and carbon residue contents, could be predicted using chemometric treatment of spectra. Furthermore, these data are relevant to combustion parameters.

\section{MATERIALS AND METHODS}

New Diffusing Support. A fiberglass cell support (Fig. 1) was tested in this study. This commercial product (provided by the Duran Group) has the following characteristics: a $15 \mathrm{~mm}$ diameter, a porosity of 2 , and $10 \mathrm{St} / \mathrm{pcs}$. Different tests were carried out to define the optimal volume of sample to be used, by considering HFOs with lower and higher viscosities. This support allowed the collection of repeatable NIR spectra of HFOs, by using the constant volume of HFO of $340 \mu \mathrm{L}$ to be impregnated.

Near-Infrared Spectra. The NIR heavy fuel spectra were recorded with a Nicolet Antaris spectrometer, 


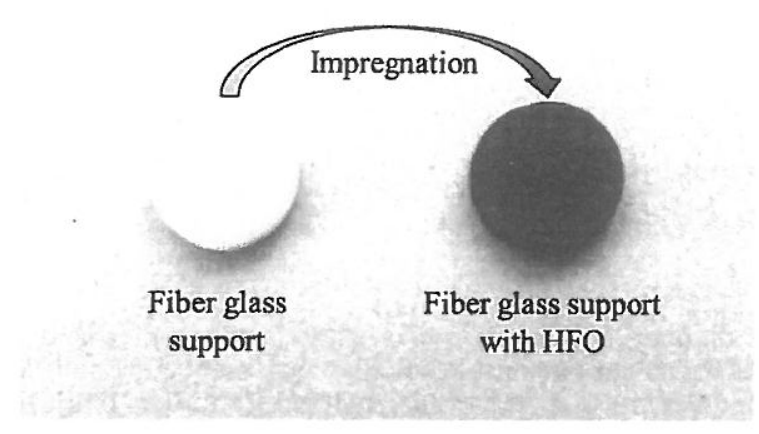

FIG. 1. Fiberglass support before and after impregnation with HFO.

zquipped with an indium gallium arsenide detector, an $\mathrm{t}_{2}$ NIR source, and a calcium fluoride/Ge beam splitter. The measurements were carried out-in an air-conditioned room at $21^{\circ} \mathrm{C}$. Fourier transform NIR spectra were recorded by collecting the NIR energy that scatters on the surface of sample, by using an integrating sphere with an accumulation of 64 scans and an optical fiber with an accumulation of 800 scans, with the surface of the fiber end directly in contact with the surface of the sample to be analyzed. All spectra were computed with a $4 \mathrm{~cm}^{-1}$ resolution, between 4000 and $10000 \mathrm{~cm}^{-1}$ (1100$2500 \mathrm{~nm}$ ), using Result Integration 2.1 software (Thermo Nicolet). A background spectrum was collected under the same conditions before each batch measurement.

Sampling for Near-Infrared Spectroscopy. Sixty-one samples of HFOs were collected from several countries; the reference analyses were conducted by Société Générale de Surveillance (SGS). For each sample, 340 $\mu \mathrm{L}$ of HFO was placed onto a fiberglass support. Each spectrum used for the classification was the average of two independent spectra obtained with two different fiberglass supports.

Principal Component Analysis (PCA). Principal component analysis is an "unsupervised" method describing a data set without any a priori knowledge of the data structure. ${ }^{16}$ PCA is oriented toward modeling the variance-covariance structure of the data matrix into a model that is based on the significant differences (significant scores) and considers noise as an error. Data are first centered and reduced, and principal components (PCs) are all orthogonal to each other. The number of PCs depends on the model complexity, but the scores have to represent the best of variance of data and explain a large part of the total variance. The first component extracts the largest source of variance. The scores and loadings of the individual PCs are recovered from each PCA model. Scores describe the variation in the samples compared with the dataset, whereas loadings describe the correlations among variables. Each vector of stone features can be considered in the space defined by the PCs as values called component scores.

Soft Independent Modeling of Class Analogy Classification (SIMCA). Soft independent modeling of class analogy (SIMCA) is the most supervised pattern recog nition used of the class-modeling techniques. ${ }^{17}$ SIMCA classification is based on disjoint PCA modeling realized for each class in the calibration set. Unknown samples are then compared to the class models and assigned to classes according to their analogy with the calibration samples. A new sample will be recognized as a member of a class if it is similar enough to the other members: otherwise, it will be rejected. Each class is modeled using separate PCA models. A model distance limit called Smax is used for classifying new samples, and Smax is calculated for the class model $m$ as follows:

$$
\operatorname{Smax}(m)=S_{0}(m) \sqrt{F_{c}}
$$

where $S_{0}$ is the average distance within the model and $F_{c}$ (Fisher criterion) is the critical value provided by the Fisher-Snedecor tables. The $F_{c}$ value depends on the percentage of risks and is generally set to $5 \% .{ }^{11}$ Class membership is defined at a significance level of $2.5 \%$ of Smax. Mean centering is applied before modeling. The number of samples used in PCA is 29, and the prediction set was formed by 32 samples.

Partial Least Squares (PLS) Regression. This supervised analysis is based on the relation between the signal intensity and the $\mathrm{Y}$ variable. ${ }^{18}$ Interference and overlapping of the spectral information may be overcome by using a powerful multicomponent analysis, such as PLS. ${ }^{19}$ This method is a sophisticated statistical approach using the full or partial spectral region rather than unique and isolated analytical bands. The algorithm is based on the ability to mathematically correlate spectral data to a property matrix of interest while simultaneously accounting for all other significant spectral factors that disturb the spectrum. It is thus a multivariate regression method that uses the full spectral region selected and is based on the use of factors. Models were built with a full cross-validation method during the calibration developments. The evaluation of the errors in the calibration was carried out by computing the standard error of calibration (SEC) after comparing the real concentration with the computed concentration for each component. The formula for the $S E C$ is as follows:

$$
S E C=\sqrt{\frac{\sum_{i=1}^{N}\left(C_{i}-C_{i}^{\prime}\right) 2}{N-1-p}}
$$

where $C^{\prime}{ }_{i}$ is the known value, $C_{i}$ is the value calculated by the calibration equation, $N$ the number of samples, and $p$ is the number of independent variables in the regression optimized by cross-validation. The standard error of prediction (SEP) gives an estimation of the prediction performance during the step of validation of the calibration equation below:

$$
S E P=\sqrt{\frac{\sum_{i=1}^{N}\left(C_{i}-C_{i}^{\prime}\right) 2}{M}}
$$

where $M$ is the number of samples in the prediction set.

All models were built by full cross-validation. 
TABLE III. Results obtained using integrating sphere in the spectral range $6500-5000 \mathrm{~cm}^{-1}$.

\begin{tabular}{|c|c|c|c|c|c|c|}
\hline $\mathrm{NIR}^{\mathrm{a}}$ & Range & $R^{2}$ & $\mathrm{RMSEC}^{\mathrm{b}}$ & LVc & $r^{2}$ & RMSEPd \\
\hline CCAI (a.u.) & $867-789$ & 0.96 & 3.53 & 8 & 0.87 & 8.78 \\
\hline Density $\left(\mathrm{kg} / \mathrm{m}^{3}\right)$ & $1007-941$ & 0.82 & 10.97 & 4 & 0.72 & 9.39 \\
\hline Carbon residue \% (w/w) & $16.7-7.7$ & 0.89 & 1.07 & 7 & 0.68 & 1.29 \\
\hline Sulfur $\%(w / w)$ & $0.22-3.49$ & 0.82 & 0.51 & 6 & 0.81 & 0.55 \\
\hline Vanadium (ppm) & $2-365$ & 0.83 & 50.87 & 7 & 0.7 & 59.89 \\
\hline Nitrogen (ppm) & $5175-1959$ & 0.60 & 543 & 4 & 0.66 & 667 \\
\hline Net energy $(\mathrm{MJ} / \mathrm{kg})$ & $41.82-39.81$ & 0.89 & 0.20 & 7 & 0.84 & 0.24 \\
\hline
\end{tabular}

b RMSEC, root mean square error of calibration.

c LV, latent variable.

${ }^{d}$ RMSEP, root mean square error of prediction.

TABLE IV. Results obtained using fiber optic in the spectral range $4000-5000 \mathrm{~cm} 1$

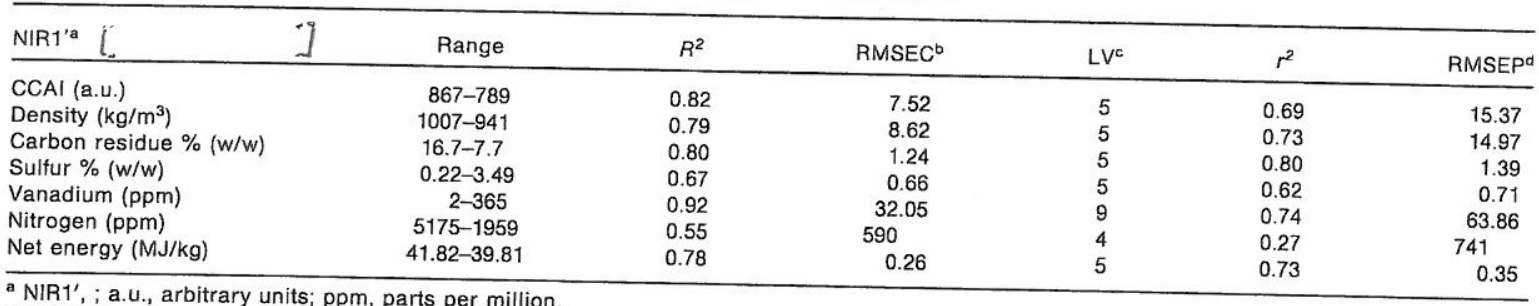

a NIR1', ; a.u., arbitrary units; ppm, parts per million.

RMSEC, root mean square error of calibration.

${ }^{\circ}$ LV, latent variable.

${ }^{\circ}$ RMSEP, root mean square error of prediction.

TABLE V. Results obtained using fiber optic in the spectral range $6500-5000 \mathrm{~cm}^{-1}$.

\begin{tabular}{|c|c|c|c|c|c|c|}
\hline NIR2'a & Range & $R^{2}$ & RMSEC $^{\mathrm{b}}$ & $\mathrm{LV}^{\mathrm{c}}$ & $r^{2}$ & RMSEP \\
\hline CCAI (a.u.) & $867-789$ & 0.79 & 8.22 & 4 & 0.7 & 15.26 \\
\hline Density $\left(\mathrm{kg} / \mathrm{m}^{3}\right)$ & $1007-941$ & 0.80 & 8.82 & 4 & 0.70 & 15.42 \\
\hline Carbon residue \% (w/w) & $16.7-7.7$ & 0.86 & 1.05 & 6 & 0.77 & 1.58 \\
\hline Sulfur \% (w/w) & $0.22-3.49$ & 0.95 & 0.27 & 10 & 0.81 & 0.52 \\
\hline Vanadium (ppm) & $2-365$ & 0.78 & 54.48 & 6 & 0.71 & 67.59 \\
\hline Nitrogen (ppm) & 5175-1959 & NC & NC & NC & NC & NC \\
\hline Net energy (MJ/kg) & $41.82-39.81$ & 0.91 & 0.17 & 8 & 0.81 & 0.32 \\
\hline
\end{tabular}

NIR2', ; a.u., arbitrary units; ppm, parts per million.

b RMSEC, root mean square error of calibration.

${ }^{c}$ LV, latent variable.

d RMSEP, root mean square error of prediction.

analyser must have to be as cheaper as possible, what induces a right choice of spectral range.

Two spectral ranges were compared using the two sampling methods: $4000-5000 \mathrm{~cm}^{-1}$ attributed to the combination of $\mathrm{C}-\mathrm{H}$ or $\mathrm{C}-\mathrm{O}$ and $6500-5000 \mathrm{~cm}^{-1}$, corresponding to the first overtone. The optimal factor was chosen as a function of the quality of quantitative analysis results on the viscosity, sulfur content, flash point, and density using a full cross-validation. For the integrating sphere, in the $4000-5000 \mathrm{~cm}^{-1}$ spectral range, the results (Table II) were very good for CCAI, density, nitrogen content, and energy and good for carbon residue and sulfur and vanadium contents. Concerning vanadium content, NIR enables to study interactions between vanadium and other functional groups, but not metal absorption directly. It should be noted that sulfur is much more concentrated in heavy fuels than in other fuels, such as gasoline and diesel, with a wide range according to the known origins. In the $6500-5000 \mathrm{~cm}^{-1}$ range, the results (Table III) were very good for CCAl, density, nitrogen content, and energy and good for carbon residue and sulfur and vanadium contents. It was possible to see a slight degradation of the results in this range compared with the previous analyses.

For the fiber optic in the region $4000-5000 \mathrm{~cm}^{-1}$, the results (Table IV) were good, but the precision of values predicted decrease compared to the results obtained from spectra collected with the integrating sphere. The impact of the loss of scattering was visible. With the fiber 

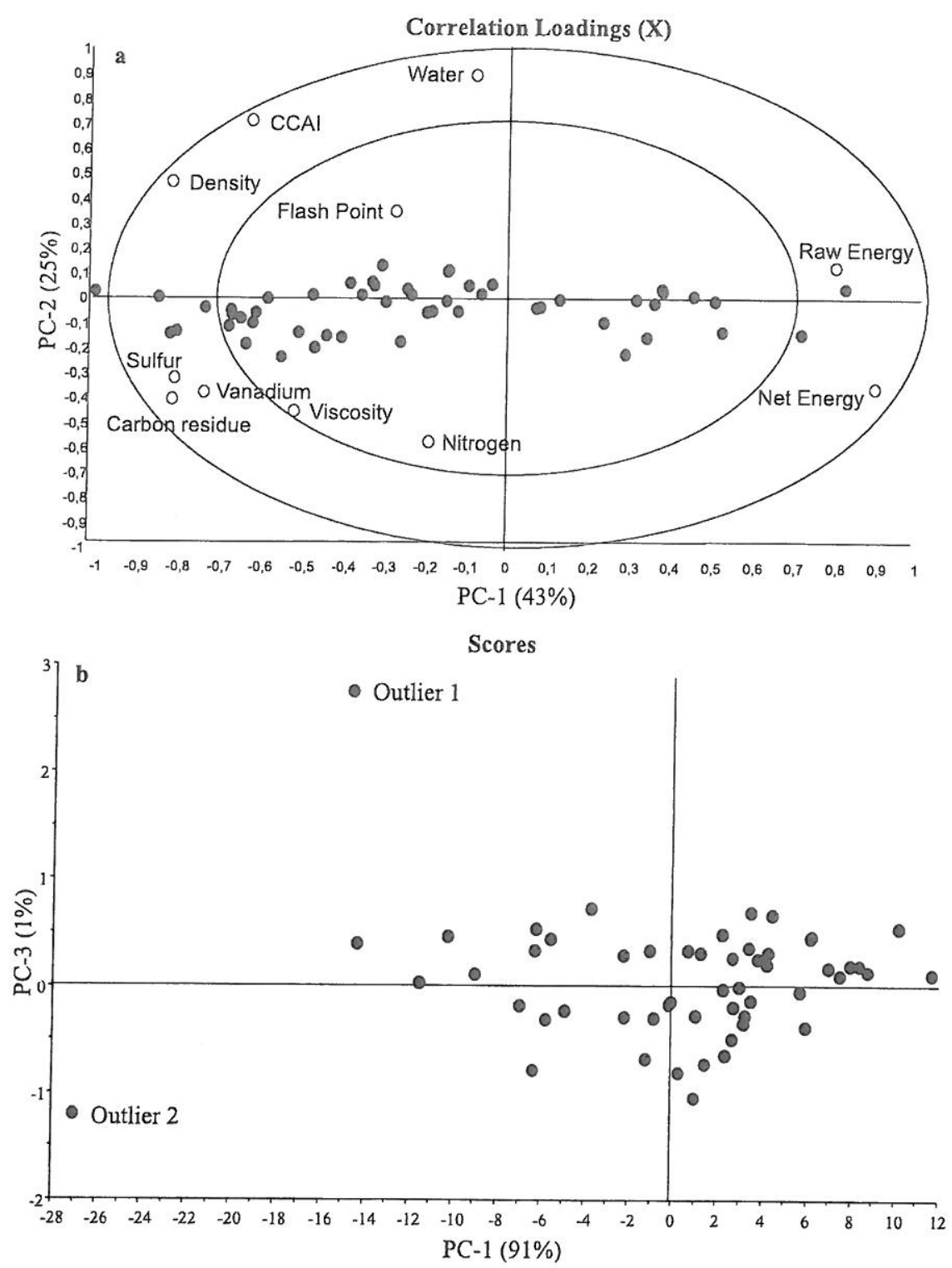

Fig. 4. PCA results on reference data (a) and NIR data (b).

211 TABLE II. Results obtained using integrating sphere in the spectral range $4000-5000 \mathrm{~cm}^{-1}$.

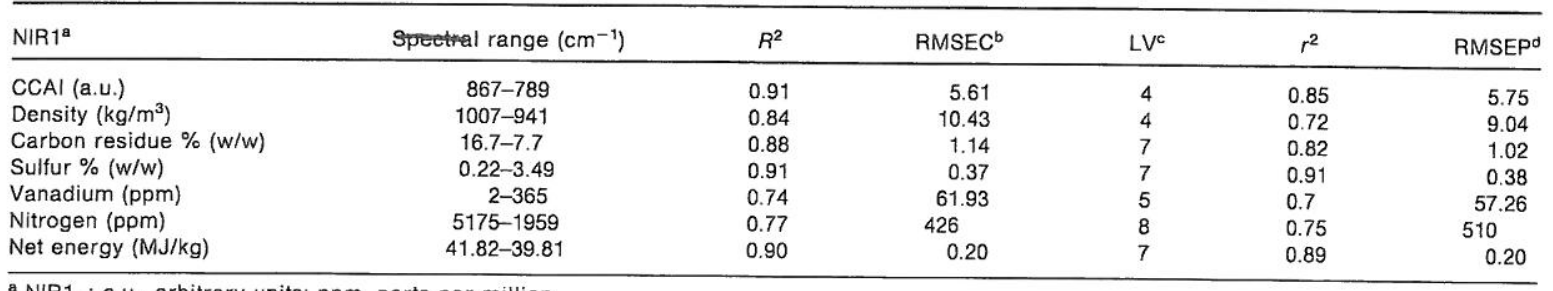

a NIR1, ; a.u., arbitrary units; ppm, parts per million.

b RMSEC, root mean square error of calibration.

c LV, latent variable.

${ }^{\circ}$ RMSEP, root mean square error of prediction. 

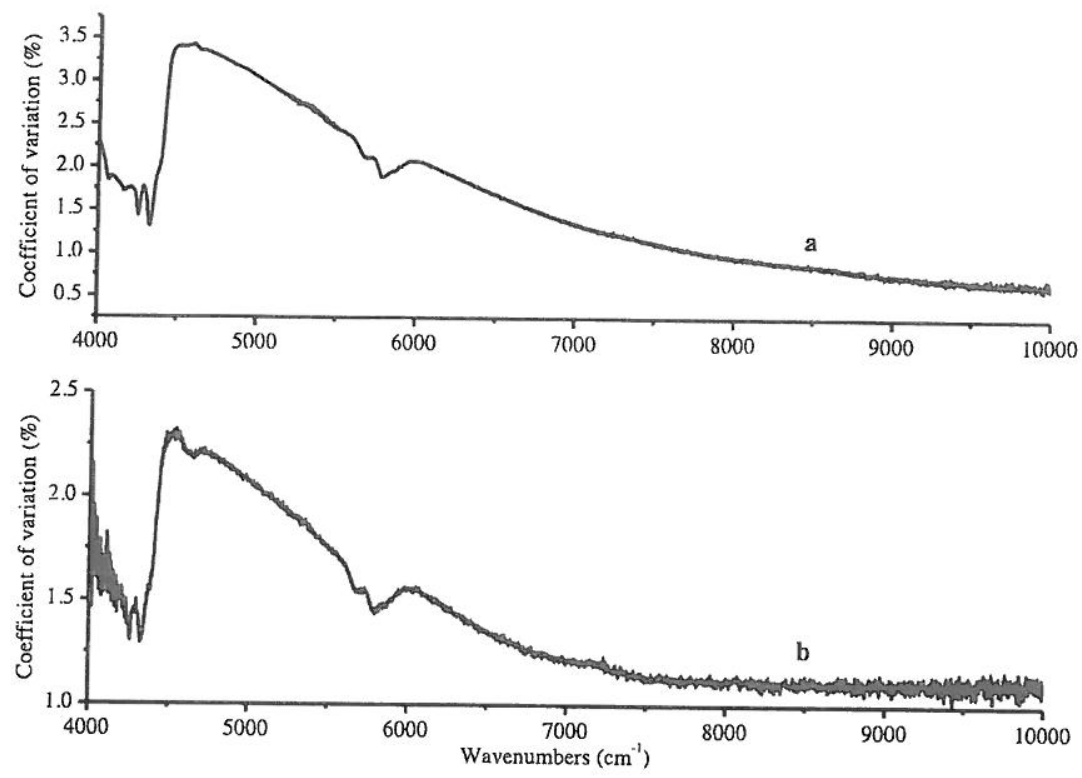

FIG. 3. Coefficient of variation for spectra of HFO collected using an integrating sphere (a) and optical fiber (b).

in the Fig. $4 a$ for the reference data and in Fig. $4 \mathrm{~b}$ for the integrating sphere data. For the reference data, the two first PCs represented $68 \%$ of the total variance ( 43 and $25 \%$, respectively). Two samples were outliers: Outlier 1 and Outlier 2. The examination of the correlation loadings given in Fig. 4a showed that Outlier 1 presented high water content and Outlier 2 low viscosity and high energy values. For the NIR data, in the space of the first and third $\mathrm{PCs}$, corresponding to $92 \%$ of the spectral variance, the same samples could be reported as outliers. Similar results were obtained for spectra collected with the optical fiber. Given that the same samples could be excluded by the two methods, discriminant analysis could be used to explore the conformity of heavy fuels samples. Twenty-nine samples with good-quality results, from several countries, were used to control the conformity of all the other samples by using SIMCA analysis. The 32 other samples were classified by using the model built from the first set of 29 samples. Identification allows assigning new objects to the class to which they show the most similarity. The results obtained for all the samples used in the prediction set show that two samples were rejected, again the same samples as those in the PCA step, whereas all the other samples are accepted as "conforming" samples. The total number of samples used in the study was 59 . These physicochemical parameters are important for the fuel combustion process. The corresponding NIR spectra were pretreated by SNV correction to eliminate drift in baseline variation ${ }^{24}$ before the construction of the PLS models. For the fiber optic sampling, the impact of the spectral resolution was studied on the carbon residue data (Table II). The calibration coefficient of determination appeared to be best at an $8 \mathrm{~cm}^{-1}$ resolution, but the predicted results were very poor; thus, $4 \mathrm{~cm}^{-1}$ resolution was selected for further analysis.

Different spectral ranges were studied to evaluate the ability to predict properties values, taking into account the purpose of the study-to develop an NIR analyzer. In particular, the detector that will be chosen to design this

TABLE I. Characteristic values of HFO used.

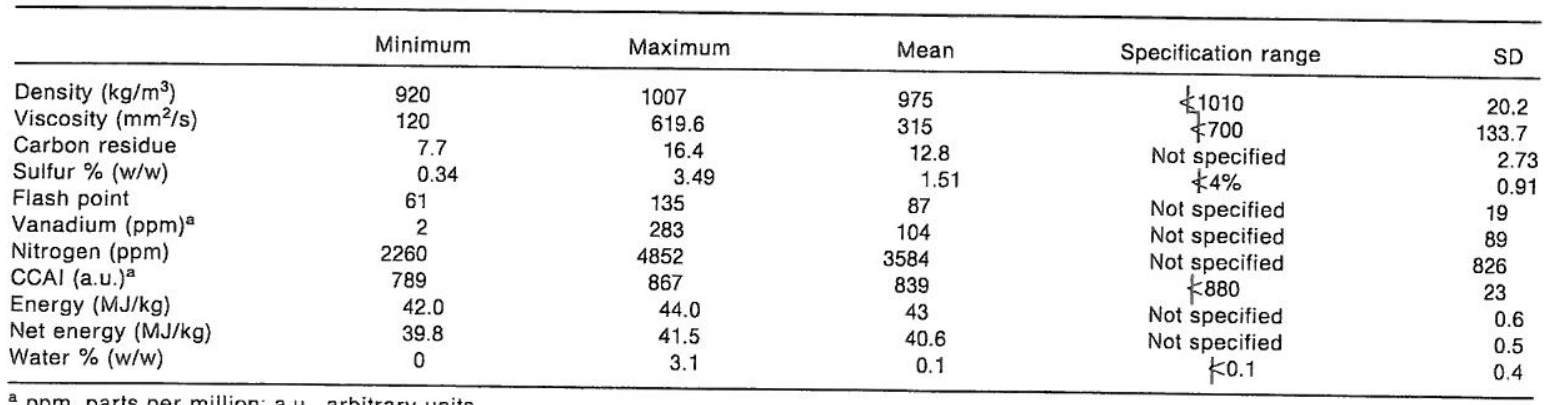

${ }^{a}$ ppm, parts per million; a.u., arbitrary units. 

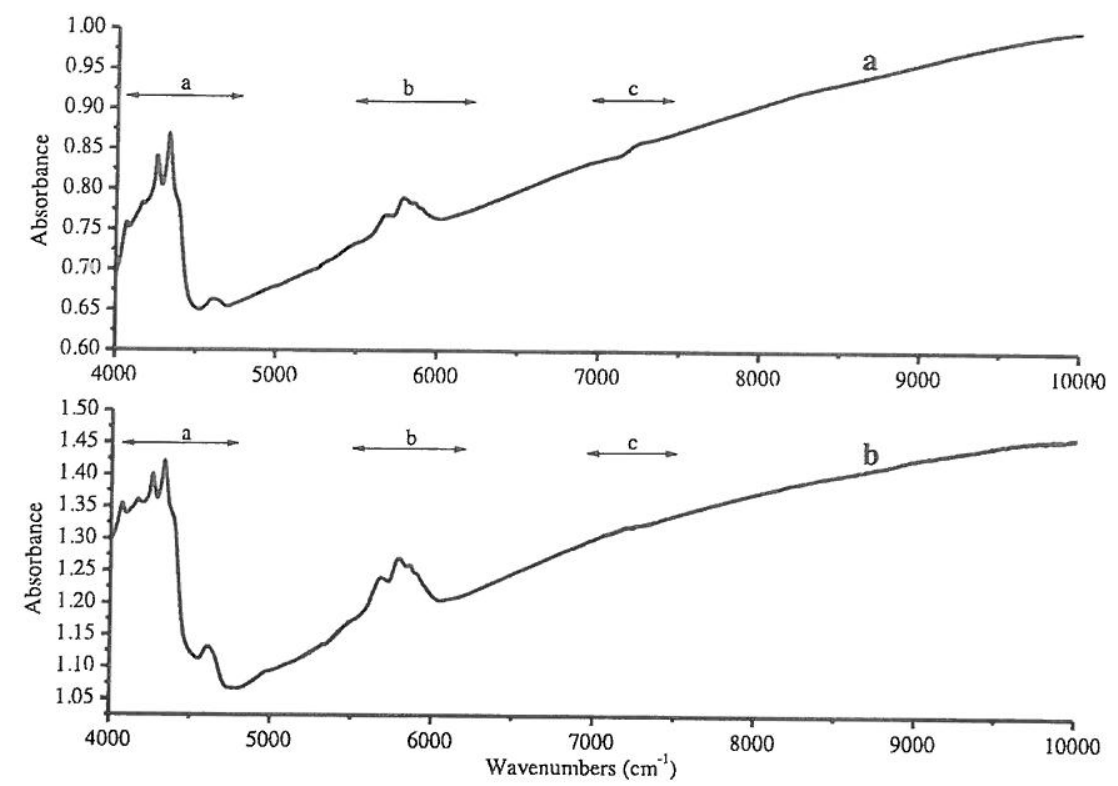

FIG. 2. NIR spectrum of HFO obtained using fiber optic (a) and an integrating sphere (b) (line a) Combination of the $\mathrm{CH}$ stretching vibration with other vibrational modes.

(line b) First overtone of $\mathrm{CH}$ stretching vibration (methyl, methylene, and ethylene groups).

(line c) Combination of the $\mathrm{CH}$ stretching vibration.

Standard Normal Variate (SNV). During the data processing, the SNV correction pretreatment was used This pretreatment is a row-oriented transformation that removes scatter effects from spectra by centering and scaling each individual spectrum.

Software. Chemometric applications are performed by The Unscrambler version X10.2 (Camo Software, Trondheim, Norway).

\section{RESULTS AND DISCUSSION}

Usually, for spectroscopic analysis, heavy fuels are placed into transmission cells with a short optical path as, for example, described by Laxalde et al.," ${ }^{20}$ who used a $0.5 \mathrm{~mm}$ heated cell. This study was a part of a project whose objective was to develop an NIR analyzer, at line to control HFO quality. The use of solvents and the need to clean the transmission cell were not acceptable in terms of specifications in various cases (e.g., coal-fired power stations, boats). We developed a new method for the analysis of heavy fuels on a fiberglass support (Fig. 1). The use of fiberglass supports offered the distinct advantages of being fast and easy to implement and it provided repeatable results. The volume of sample was optimized to obtain a totally impregnated support without HFO oozing. In our case, $340 \mu \mathrm{L}$ represented an appropriate compromise. Even if this value is not ideal, it is the same scale of size as the value used by Laxalde et al. ${ }^{17}$ Two methods were used to collect the FT-NIR spectra: ${ }^{21,22}$ an integrating sphere and an optical fiber. For the fiber optic method, the number of scans $(800)$ accumulated to record the spectra was high to obtain a good signal-to-noise ratio. The spectra of the same sample obtained by both ways (Figs. $2 a$ and $2 b$ ) showed some variations. The spectrum obtained using the fiber optic appeared to be less specific in the $4000-4500 \mathrm{~cm}^{-1}$ range, but the general aspect was similar: (1) combination of the $\mathrm{CH}$ stretching vibration with other vibrational modes, (2) first overtone of $\mathrm{CH}$ stretching vibration (methyl, methylene, and ethylene groups), and (3) combination of the $\mathrm{CH}$ stretching vibration. ${ }^{23}$ To evaluate the repeatability of the sampling, the standard deviation was calculated on 10 spectra of a same sample (Figs. 3a and $3 b)$. For each sample, two glass fibers were used to include the variability of the fiberglass support in the model, and five spectra were collected on each support using the integrating sphere and fiber optic. The results showed that the standard deviation is less than $2.5 \%$ for all the wavenumbers and that there was no significant variation between the two sampling methods. The spectral range that presented the highest variation corresponded to the lower absorption zone $4900-4600$ $\mathrm{cm}^{-1}$. Thus, the use of a fiberglass support is a suitable means for heavy fuel analysis. The use of the classical cell involves problems of cleaning with an organic solvent and regulating temperature. Physicochemical properties, such as density, CCAl, viscosity, flash point, energy, and net energy, and the nitrogen, vanadium, sulfur, water, and carbon residue contents of samples were measured using reference techniques by the SGS laboratory. Table I shows minimum and maximum values of each parameter for the samples in the database and the ranges of values. Clearly, some samples were outside the limits, especially for water content.

To check whether the sample presentation maintains sample composition of the HFOs, PCA was applied to reference data and to NIR spectra. The results are given 
optic in the region $6500-5000 \mathrm{~cm}^{-1}$ (Table V), the results obtained were good for CCAI, vanadium content, net energy, and density; correct for sulfur content; but poorer for carbon residue and nitrogen content.

\section{CONCLUSIONS}

This preliminary study showed the feasibility of analyzing heavy fuels by NIR spectroscopy. The use of a diffusing support allowed freedom from cleaning of the tank. The classification of samples as "conforming "or "not conforming" can be done on reference data (e.g. CCAl; density; viscosity; flash point; sulfur, vanadium, and nitrogen contents; energy and net energy) as well as on spectral data. Thus, the physicochemical characteristics were successfully predicted by chemometrics treatment from spectral data. The accuracy of analysis depends on the sampling, but with a fiber optic in the range of first overtone, the principal physicochemical data were correctly predicted. This point is very important for a better environmentally friendly use of these fuels.

\section{ACKNOWLEDGMENTS}

This study was financially supported by French State and territorial collectivities, and a collaborative project supported by Mer PACA and CAPénergies, both competitiveness centers.

1. R.M. Balabin, R.Z. Safieva. "Moisture Content Determination in Solid Biofuels by Dielectric and NIR Reflection Methods". Fuel. Solid Biofuels by Dielectr

2. P.D. Jensen, H. Hartmann, T. Böhm, M. Temmerman, F. Rabier, M. Morsing. "Moisture Content Determination in Solid Biofuels by Dielectric and NIR Reflection Methods". Biomass Bioenergy. 2006. 30(11): 935-943.

3. A. Permanyer, L. Douifi, M. Alberdi, C. Rebufa, J. Kister. "American Congress on Organic Geochemistry". Colombia: Cartagena de Indias, 2002. October 20-24, Pp. 111-114.

4. L.D. Stasiuk, L.R. Snowdon. "Fluorescence Micro-Spectrometry of Synthetic and Natural Hydrocarbon Fluid Inclusions: Crude Oi Chemistry, Density and Application to Petroleum Migration". Appl. Geochem. 1997. 12(2): 229-241.

5. H.W. Hagemann, A. Hollerbach. "The Fluorescence Behavior of Crude Oils with Respect to Their Thermal Maturation and Degradation". Org. Geochem. 1986. 10(1-3): 473-480.

6. J. Kister, M. Guiliano, C. Largeau, S. Derenne, E. Casadevall. "Characterization of Chemical Structure, Degree of Maturation and Oil Potential of Torbanites by Quantitative FT-IR Spectroscopy". Fuel. 1990. 69(11): 1356-1361.

7. J. Kister, N. Pieri, R. Alvarez, M.A. Dies, J.J. Pis. "Effects of Preheating and Oxidation on Two Bituminous Coals Assessed by Synchronous UV Fluorescence and FTIR Spectroscopy". Energy Fuels. 1996. 10(4): 948-957.

8. N. Pieri. "Etude du Vieillissement Simule et in Situ des Bitumes Routiers par IRTF Et Fluorescence UV en Excitation-Emission Synchrones". Thèse de I'Universite d'Aix-Marseille III. 1994.
9. J. Kister, M. Guiliano, G. Mille, H. Dou. "Changes in the Chemical Structure of Low Rank Coal After Low Temperature Oxidation or Demineralization by Acid Treatment: Analysis by FT-IR and UV Fluorescence". Fuel. 1988. 67(8): 1076-1082.

10. J. Kister, P. Doumenq, E. Davin, G. Mille. "Mesure Du Degré D'Évolution de Charbons par Spectroscopie de Fluorescence UV (EES)". Comptes rendus de l'Académie des Sciences, Paris. 1992. 315(2): 149-152.

11. O. Abbas, C. Rebufa, N. Dupuy, A. Permanyer, J. Kister. "FTIRMultivariate Curve Resolution Monitoring of Photo-Fenton Degradation of Phenolic Aqueous Solutions: Comparison with HPLC as a Reference Method". Talanta. 2008. 77: 200-209.

12. N. Aske, H. Kallevik, E.E. Johnsen, J. Sjöblom. "Asphaltene Aggregation from Crude Oils and Model Systems Studied by High-Pressure NIR Spectroscopy". Energy Fuels. 2002. 16(5): 12871295.

13. S. Amat-Tosello, N. Dupuy, J. Kister. "Contribution of External Parameter Orthogonalisation for Calibration Transfer in Short Waves-Near Infrared Spectroscopy Application to Gasoline Quality". Anal. Chim. Acta. 2009. 642(1-2): 6-11.

14. R.M. Balabin, R.Z. Safieva, E.L. Lomakina. "Near-Infrared (NIR) Spectroscopy for Motor Oil Classification: From Discriminant Analysis to Support Vector Machines". Microchem. J. 2011. 98(1): 121-128.

15. R. Fernández-Varela, J.M. Andrade, S. Muniategui, D. Prada, F. Ramirez-Villalobos. "The Comparison of Two Heavy Fuel Oils in Composition and Weathering Pattern, Based on IR, GC-FID and GC MS Analyses: Application to the Prestige Wreckage". Water Res. 2009. 43(4): 1015-1026

16. O. Galtier, O. Abbas, Y. Le Dréau, C. Rébufa, J. Kister, J. Artaud, N. Dupuy. "Comparison of PLS1-DA, PLS2-DA, and SIMCA for Classification by Origin of Crude Petroleum Oils by MIR and Virgin Olive Oils by NIR for Different Spectral Regions". Vib. Spectrosc. 2011. 55(1): 132-140.

17. S. Wold, M. Sjöström. "SIMCA: A Method for Analyzing Chemical Data in Terms of Similarity and Analogy". In: B.R. Kowalski, editor. Chemometrics Theory and Application. Washington, DC: American Chemical Society, 1977. Pp. 243-282.

18. H. Martens. "Factor Analysis of Chemical Mixtures. Non-Negative Factor Solutions for Cereal Amino Acid Data". Anal. Chim. Acta. 1979. 112(4): 423-441

19. Y.L. Liang, O.M. Kvalheim. "Robust Methods for Multivariate Analysis-A Tutorial Review". Chemom. Intell. Lab. Syst. 1996 32(1): 1-10.

20. J. Laxalde, C. Ruckebusch, O. Devos, N. Caillol, F. Wahl, L. Duponchel. "Characterisation of Heavy Oils Using Near-Infrared Spectroscopy: Optimisation of Pre-Processing Methods and Variable Selection". Anal. Chim. Acta. 2011. 705(1-2): 227-234.

21. N. Aske, H. Kallevik, J. Sjöblom. "Determination of Saturate, Aromatic, Resin, and Asphaltenic (SARA) Components in Crude Oils by Means of Infrared and Near-Infrared Spectroscopy". Energy Fuels. 2011. 15(5): 1304-1312.

22. A. Hannisdal, P.V. Hemmingsen, J. Sjöblom. "Group-Type Analysis of Heavy Crude Oils Using Vibrational Spectroscopy in Combination with Multivariate Analysis". Ind. Eng. Chem. Res. 2005. 44(5): 13491357.

23. J. Workman, Jr., L. Weyer. "Practical Guide to Interpretive NearInfrared Spectroscopy". Boca Raton, FL: CRC Press, 2007.

24. M. Friedel, C.D. Patz, H. Dietrich. "Comparison of Different Measurement Techniques and Variable Selection Methods for FTMIR in Wine Analysis". Food Chem. 2013. 141(4): 4200-4207. 